\title{
Antibiotic susceptibility pattern of bacterial strains isolated from different clinical samples in Multan, Pakistan
}

\author{
Hafsa Alam and Humaira Yasmeen* \\ Department of Microbiology and Molecular Genetics, The Women University Multan-Pakistan \\ *Corresponding author's email: humaira.6127@wum.edu.pk \\ Citation \\ Hafsa Alam and Humaira Yasmeen. Antibiotic susceptibility pattern of bacterial strains isolated from different \\ clinical samples in Multan, Pakistan. Pure and Applied Biology. Vol. 9, Issue 4, pp2175-2181. \\ http://dx.doi.org/10.19045/bspab.2020.90232
}

Received: 09/03/202

Revised: 30/05/2020

Accepted: 09/06/2020

Online First: 29/06/2020

\section{Abstract}

Rapid evolution of resistance in bacteria towards antibiotics has dramatically become a global health crisis. The aim of present study was to check the prevalence and antimicrobial sensitivity of bacteria present in clinical samples. Two hundred and seventy different clinical samples were examined in laboratory of the Chaudhary Pervaiz Elahi Institute of Cardiology, Multan Pakistan. Clinical isolates were isolated on MacConkey agar, blood agar and Cystine Lactose Electrolyte Deficient Agar (CLED Agar). The isolated strains were tested for antimicrobial susceptibility against the panel of 27 antibiotics. Out of 270 sample, 91(33.7\%) showed microbial load. Staphylococcus aureus, Pseudomonas spp., Escherichia coli, Klebsiella spp. and Candida spp. were commonly isolated. Staphylococcus aureus showed the highest prevalence as monoresistant and polyresistant strain. The malpractice of self-medication with unrestricted supply of medicines have played an important role in antimicrobial resistance.

Keywords: Antimicrobial resistance; Escherichia coli; ESBL; Zone of inhibition

\section{Introduction}

World Health Organization (WHO) defines antimicrobial resistance as "resistance of a microorganism to an antimicrobial medicine to which it was previously sensitive." When microorganism develops resistance to antimicrobials, the standard treatments become ineffective thereby limiting the medical treatment of these infectious diseases. The infection persists and may spread to others $[1,2]$. Failure in identification of bacterial pathogen dramatically changes the health scenario of patients and is responsible for yearly increase in deaths $[3,4]$. Bacterial resistance not only has become global health epidemic but also has brutally increased the cost of treatment [4]. Poor hygiene practices and ineffective prevention measures along with misuse of antibiotics have contributed in development of resistant bacterial pathogens. Besides, insufficient number of new drugs has also worsened the situation [1].

The situation of resistant pathogens in Pakistan is alarming. Failure to provision of basic healthcare facilities and lack of awareness about hygienic life style has compromised many lives. In addition, it has added deficit in understanding and compliance of biosafety issues of community and healthcare institutions in Pakistan. The malpractice of using medicine without 
consulting medical doctor has paved the path towards resistance of bacterial pathogens [5]. According to recent report of National Action Plan for Antimicrobial Resistance, excessively registered products, misleading advertisements, polypharmacy, irrational prescriptions, unrestricted availability of drugs, lack of surveillance systems and experts and widespread use of antibiotics in poultry, animals and agriculture were identified as major challenges and issues [6, 7]. As a foremost action there should be a ban on the purchase of non-prescribed drugs [8, 9]. There is a lack of active national surveillance program to establish policy legislation. Therefore, there is dire need of international and national collaborative work with government sector to address this growing uncontrolled microbial resistance in Pakistan [7]. The bacteriological profile and antibiogram pattern of patients usually vary due to different environmental factors. Therefore, this study aims to study bacteriological profile of commonly bacterial isolates from different clinical samples i.e. urine, blood, wounds, and sputum, pus, to study their antibiogram pattern and to determine prevalence of multidrug resistant (MDR) and extended spectrum beta lactamase (ESBL).

\section{Materials and methods}

\section{Sampling and isolation}

This retrospective study was conducted in Chaudhary Pervaiz Elahi Institute of Cardiology, Multan Pakistan. Laboratory records from March 2017 to March 2018 were obtained which include both demographic as well as clinical record. Two hundred and seventy samples from eight different clinical specimens were collected. These include urine, blood, sputum, pus, central venous pressure tip (CVP Tip), arterial line tip, tracheal tube and Foleys tip. For the isolation of bacteria, specimens were cultured on MacConkey agar, blood agar and cystine lactose electrolyte deficient agar.
After overnight incubation at $37^{\circ} \mathrm{C}$, bacterial growth was observed. Bacteria were characterized by colony morphology and further confirmed by gram staining and biochemical tests i.e. catalase test, oxidase test, coagulase test and germ tube test.

\section{Antimicrobial assay}

Muller Hinton (MH) agar was used for antimicrobial susceptibility testing using Kirby-Bauer Disc diffusion method [10]. This test was performed against the panel of 27 antibiotics that include Amikacin $(30 \mu \mathrm{g})$,

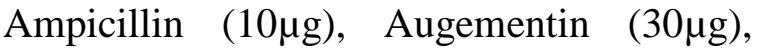

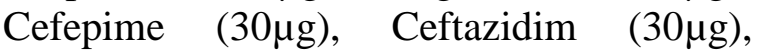
Ceftriaxone $(30 \mu \mathrm{g})$, Cefuperazone $(105 \mu \mathrm{g})$, Cefuroxime $(30 \mu \mathrm{g})$, Cephradine $(30 \mu \mathrm{g})$, Ciprofloxacin $(5 \mu \mathrm{g})$, Clarithromycin $(15 \mu \mathrm{g})$, Clindamycin $(2 \mu \mathrm{g}), \quad$ Ecasil $(30 \mu \mathrm{g})$, Erythromycin $(15 \mu \mathrm{g})$, Fusidic acid $(10 \mu \mathrm{g})$, Gentamicin $(10 \mu \mathrm{g})$, Imipenem $(10 \mu \mathrm{g})$, Linezolid (30 $\mathrm{g})$, Meropenem $(10 \mu \mathrm{g})$, Moxifloxacin $(5 \mu \mathrm{g})$, Nitrofurantoin $(300 \mu \mathrm{g})$, Oxacillin $(1 \mu \mathrm{g})$, Romicef $(30 \mu \mathrm{g})$, Sulzone $(105 \mu \mathrm{g})$, Tazobactum $(110 \mu \mathrm{g})$, Teicoplanin $(30 \mu \mathrm{g})$, Vancomycin $(30 \mu \mathrm{g})$. Briefly, test colony was spread evenly on $\mathrm{MH}$ agar and left for 5 minutes at room temperature so that inoculum get absorbed. Afterwards, commercially available antibiotic discs were impregnated aseptically and incubated at $37^{\circ} \mathrm{C}$ for $24 \mathrm{~h}$. Zone of inhibition $(\mathrm{mm})$ was measured after 24h. Depending upon diameter of zone of inhibition against each antibiotic disc, strains were classified as resistant, intermediate and sensitive. In absence of zone of inhibition, strain is considered as resistant which means that antibiotic is ineffective against test strain. In presence of zone of inhibition, the strain is considered as sensitive and antibiotic is effective against test strain.

\section{Statistical analysis}

The statistical analysis was performed using the SPSS Statistics 22.0. The distribution frequency between gender was compared. The data was also analysed seasonally i.e. 
summer, winter, autumn and spring. The Chisquare test was used to compare the prevalence, sensitivity and resistance rates between different types of specimens.

\section{Results}

\section{Clinical characteristics}

Two hundred and seventy samples were examined in given time. The male to female distribution ratio was $2: 1$ i.e. $87(32.2 \%)$ samples were of females and $183(67.7 \%)$ were of males (Table 1). Out of 270 sample examined, 91(33.7\%) showed microbial growth; $86 \quad(94.5 \%)$ samples showed bacterial growth while $5(5.5 \%)$ samples showed fungal growth. Among different types of clinical specimens, blood samples were the highest 116 (43\%) followed by 76 (28.1\%) pus, 30 (11.1\%) urine, 17 (6.3\%) CVP tip, 16 (5.9\%) Foleys tip, 9 (3.3\%) arterial line tip, $3(1.1 \%)$ sputum and 3 $(1.1 \%)$ tracheal tube samples. It was noticed that proportion of Gram-positive bacteria was higher than Gram negative i.e. 60(70\%) and $26(30 \%)$ respectively. In different microbial types isolated, most prevalent bacterial type was S. aureus (65.93\%). Other microbes isolated were Pseudomonas spp. (19.78\%), Candida spp. (5.5\%), Escherichia coli (E. coli) $(5.5 \%)$ and Klebsiella spp. (3.3\%).

Multidrug resistant (MDR) and extensive drug resistant (XDR)

Bacterial isolates that showed resistance against more than one drug were categorized as multidrug resistant (MDR) and isolates that were resistant against more than two classes of drug were categorized as extensive drug resistant (XDR). The most commonly reported MDR and XDR was $S$. aureus MDR 25 (41.67\%) and XDR 35 (58.33\%). In Pseudomonas spp. MDR and XDR were 3 $(16.67 \%)$ and $15(83.33 \%)$ respectively. However, the frequency and distribution of E. coli as MDR and XDR was same $1(20 \%)$ (Table 2). Distribution of MDR and XDR isolates from males and females was merely same. The frequency of MDR in males and females was $18(32.73 \%)$ and $11(35.49 \%)$ and XDR was $34(61.82 \%)$ and $17(54.84)$ (Table 3). However, the distribution of multidrug resistant (MDR) in different specimens varied. Out of 42 bacterial isolates from pus sample, 18 (42.85\%) were MDR and $23(54.76 \%)$ were XDR. From blood samples $7(43.75 \%)$ were MDR and 9 (56.25\%) were XDR. 1 (14.29\%) MDR were present in Foleys tip, CVP tip and arterial line tip. 5 (71.42\%), 3 (100\%), 2 (28.57\%), 6 $(85.71 \%)$ and $3(100 \%)$ XDR were isolated from CVP tip, Tracheal tube, Urine, Foleys tip and Sputum respectively (Table 4).

Extended spectrum beta lactamases (ESBL)

Some bacteria are resistant against beta lactamase antibiotics such as penicillin, carbapenem and cephalosporin. They were termed as extended spectrum beta lactamases (ESBL). The two main bacteria that produce ESBLs are E. coli and Klebsiella spp. All the three strains of Klebsiella spp. were ESBLs. While the frequency and percentage of $E$. coli as ESBL were $3(60 \%)$ (Table 2). ESBLs was equally distributed between males and females i.e. $3(5.45 \%)$ and $3(9.67 \%)$ respectively (Table 3$)$. Like MDR and XDR, the distributions of ESBL bacteria among different specimens were different i.e. 4 (57.14\%), 1 (14.29\%) and 1 (2.39\%) respectively (Table 4).

\section{Discussion}

Antibiotics were used initially for medical applications but have expanded their use in agriculture in the 1950s [11]. It is difficult to imagine optimal health without an umbrella of antibiotics to use when needed [12]. Up to 95\% of adults in India and Pakistan carry bacteria that are resistant to $\beta$-lactam antibiotics in comparison to $10 \%$ of adults in the Queens area of New York [13]. Like previously reported in this study also MDR were present with high frequency $(33.7 \%)$ in clinical specimens including urine, blood, sputum, pus, central venous pressure tip 
(CVP Tip), arterial line tip, tracheal tube and Foleys tip from a local hospital based diagnostic laboratory. Contradictory to Gandra et al. [14] who found 14\% culture positive for microbial growth. This low frequency could be due to monospecimen type i.e. all samples were blood samples compared to our diverse sample types. Similar to our findings Saeed et al. [15] also reported common isolates Escherichia coli, Staphylococcus aureus, Pseudomonas aeruginosa, Klebsiella pneumoniae and Acinetobacter baumanii recovered from clinical specimens [15].

Table 1. Sample characteristics

\begin{tabular}{|c|c|c|}
\hline Clinical isolates & Frequency & Percentage $(\%)$ \\
\hline \multicolumn{3}{|c|}{ Sex } \\
\hline Male & 183 & 67.8 \\
\hline Female & 87 & 32.2 \\
\hline \multicolumn{3}{|c|}{ Specimen type } \\
\hline Blood & 116 & 43.0 \\
\hline Pus & 76 & 28.1 \\
\hline Urine & 30 & 11.1 \\
\hline CVP tip & 17 & 6.3 \\
\hline Foleys tip & 16 & 5.9 \\
\hline Arterial line tip & 9 & 3.3 \\
\hline Sputum & 3 & 1.1 \\
\hline Tracheal tube & 3 & 1.1 \\
\hline \multicolumn{3}{|c|}{ Microbe isolated } \\
\hline Bacteria & 86 & 94.5 \\
\hline Fungi & 5 & 5.5 \\
\hline \multicolumn{3}{|c|}{ Culture characteristics (only for bacterial isolates) } \\
\hline Gram positive & 60 & 70 \\
\hline Gram negative & 26 & 30 \\
\hline Total & 86 & 100 \\
\hline \multicolumn{3}{|c|}{ Isolated Microbe type } \\
\hline S.aureus & 60 & 65.93 \\
\hline Pseudomonas spp. & 18 & 19.78 \\
\hline Candida spp. & 5 & 5.5 \\
\hline E.coli & 5 & 5.5 \\
\hline Klebsiella spp. & 3 & 3.3 \\
\hline
\end{tabular}


Table 2. Percentages of MDR, XDR and ESBL in different bacterial isolates

\begin{tabular}{|c|c|c|c|}
\hline Bacterial isolates & MDR $(\boldsymbol{\%})$ & XDR $(\%)$ & ESBL $(\%)$ \\
\hline $\mathbf{n}=\mathbf{8 6}$ & $\mathbf{n = 2 9}$ & $\mathbf{n = 5 1}$ & $\mathbf{n = 6}$ \\
\hline S. aureus $(n=60)$ & $25(41.67)$ & $35(58.33)$ & 0 \\
\hline E.coli $(n=5)$ & $1(20)$ & $1(20)$ & $3(60)$ \\
\hline Klebsiella spp. $(\mathrm{n}=3)$ & 0 & 0 & $3(100)$ \\
\hline $\begin{array}{c}\text { Pseudomonas } \text { spp. } \\
(\mathrm{n}=18)\end{array}$ & $3(16.67)$ & $15(83.33)$ & 0 \\
\hline
\end{tabular}

Table 3. Distribution of MDR, XDR and ESBL in males and females

\begin{tabular}{|c|c|c|c|}
\hline Gender & MDR (\%) & XDR (\%) & ESBL (\%) \\
\hline Male $(\mathrm{n}=55)$ & $18(32.73)$ & $34(61.82)$ & $3(5.45)$ \\
\hline Female $(\mathrm{n}=31)$ & $11(35.49)$ & $17(54.84)$ & $3(9.67)$ \\
\hline
\end{tabular}

Table 4. Distribution of MDR, XDR and ESBL in different specimen types

\begin{tabular}{|c|c|c|c|}
\hline Specimen type & MDR $(\%)$ & XDR (\%) & ESBL (\%) \\
\hline A line tip $(\mathrm{n}=1)$ & $1(100)$ & - & - \\
\hline Blood $(\mathrm{n}=16)$ & $7(43.75)$ & $9(56.25)$ & $1(2.39)$ \\
\hline Pus $(\mathrm{n}=42)$ & $18(42.85)$ & $23(54.76)$ & $1(14.29)$ \\
\hline CVP tip $(\mathrm{n}=7)$ & $1(14.29)$ & $5(71.42)$ & - \\
\hline $\begin{array}{c}\text { Tracheal tube } \\
(\mathrm{n}=3)\end{array}$ & - & $3(100)$ & $4(57.14)$ \\
\hline Urine $(\mathrm{n}=7)$ & $1(14.29)$ & $2(28.57)$ & - \\
\hline Foleys tip $(\mathrm{n}=7)$ & $1(14.29)$ & $6(85.71)$ & - \\
\hline Sputum $(\mathrm{n}=3)$ & - & $3(100)$ & \\
\hline
\end{tabular}

In our study the frequencies of MDR, XDR and ESBL were $33.73 \%, 59.3 \%$ and $6.97 \%$. In the same way Sabir et al. [2] reported $87.17 \%$ of the positively cultured specimens in which MDR strains were prevalent with a frequency of $20.59 \%$. Staphylococcus aureus was the most abundant $(65.93 \%)$ higher than reported previously i.e. $30 \%$ to $15.49 \%[2,16,17]$. However, Pseudomonas spp. in our study was $19.78 \%$ while in study of Adedeji et al. [17], the prevalence of Pseudomonas spp. was predominately about $50 \%$. Ogisi and Osamar [18] reported a prevalence of $31 \%$ for Pseudomonas spp. A total of $3(10 \%)$ MDR Pseudomonas spp. were reported similar to previously reported. Likewise, Narteen et al. [19] also reported multi-drug resistant Pseudomonas aeruginosa in clsainical samples.

The prevalence of $E$. coli in our study was low $(5.5 \%)$ compared to another study which reported a frequency of $26.77 \%$ [2]. Other also reported higher frequency i.e. $47.4 \%$ by Anagaw et al. [20], 41.7\% by Hafeez et al. [21]. However, the frequencies of MDR in $E$. coli were $20 \%$. The percentage of MDR E.coli reported by Hospenthal et al. [22] was $57 \%$. The difference in findings could be due to different environment, different specimens and varying time period of research. The 
$3.3 \%$ frequency of Klebsiella spp. was much lower than reported by Latif et al. [23] i.e. $24.1 \%$. None of the Klebsiella spp. strains isolated were MDR which is contradicted to Sabir et al. [2] who reported a prevalence rate of $22.58 \%$ in clinical samples e.g. tissue, urine, bone and pus samples of clinic. In this study Candida spp. was also isolated of about $5.5 \%$ and in the study of Sabir et al. [2] $26.9 \%$ of Candida spp. was isolated. The prevalence of Candida spp. in blood cultures was $5.8 \%$ [14]. While in our study no candida spp. was isolated from blood samples.

\section{Conclusion}

In conclusion, this study showed that Escherichia coli, Staphylococcus aureus, Pseudomonas spp., Klebsiella spp. and Candida spp. were the most common isolates recovered from clinical specimens. Staphylococcus aureus was more prevalent as compared to other isolates. The MDR strains of Staphylococcus aureus was high. The higher rate of ESBL strains of Klebsiella spp. were reported in this study. Emergent action against uncontrolled use of antibiotics is needed.

\section{Authors' contributions}

Conceived and designed the experiments: HA \& HY. Performed the experiments: HA. Analyzed the data: HA \& HY. Contributed reagents/materials/analysis tools: HY. Wrote the paper: HA \& HY.

\section{References}

1. Shaikh BT (2017). Antimicrobial resistance in Pakistan: a public health issue. J Ayub Med Coll, Abbottabad 29(2): 184-185.

2. Sabir R, Alvi SFD, \& Fawad A (2013). Antimicrobial susceptibility pattern of aerobic microbial isolates in a clinical laboratory in Karachi-Pakistan. Pak $J$ Med Sci 29(3): 851-5.

3. Pahlow S, Meisel S, Cialla-May D, Weber K, Rosch P, \& Popp J (2015). Isolation and identification of bacteria by means of Raman spectroscopy. $A d v$ Drug Deliv Rev 89: 105-120.

4. Syal K, Mo M, Yu H, Iriya R, Jing W, Guodong S, Wang S, Grys TE, Haydel SE, \& Tao N (2017). Current and emerging techniques for antibiotic susceptibility tests. Theranostics 7(7): 1795-1805.

5. Hussain T (2015). Pakistan at the verge of potential epidemics by multi-drug resistant pathogenic bacteria. Adv Life Sci 2(2): 46-47.

6. Khan EA (2018). Situation analysis report on antimicrobial resistance in Pakistan-findings and recommendations for antibiotic use and resistance. Internet]. The Global Antibiotic Resistance Partnership (GARP), Pakistan [cited 2018 Mar 19]. Available from: https://www. cddep. org/publications/garp-Pakistansituation-analysis.

7. Saleem Z, \& Hassali MA (2019). Traveler's take heed: Outbreak of extensively drug resistant (XDR) typhoid fever in Pakistan and a warning from the US CDC. Travel Med Infect Dis 27: 127.

8. Aziz MM, \& Fang Y (2019). Pakistan should immediately curb the sale of nonprescribed antibiotics from community pharmacies. Inter J Health Plann Manag 34(2): e1376-e1377.

9. Ali I, Ahmad J, Khan AU, Khan TM, Khan J, \& Ul-Haq Z (2016). Selfmedication and non-adherence with antibiotics: the current situation in Pakistan. J Pharm Pract Res 46(1): 3437.

10. Yasmeen H, \& Hasnain S (2015). In vitro antioxidant effect of Camellia sinensis on human cell cultures. Pak $J$ Pharm Sci 28(5): 1573-1581.

11. Graham DW, Knapp CW, Christensen BT, McCluskey S, \& Dolfing J (2016). Appearance of $\beta$-lactam resistance genes 
in agricultural soils and clinical isolates over the $20^{\text {th }}$ century. Sci Rep, 6: 21550.

12. Blaser MJ (2016). Antibiotic use and its consequences for the normal microbiome. Sci 352(6285): 544-545.

13. Reardon S (2014). Antibiotic resistance sweeping developing world. Nature News 509(7499): 141.

14. Gandra S, Mojica N, Klein EY, Ashok A, Nerurkar V, Kumari M, Ramesh U, Dey S, Vadwai V, Das BR, \& Laxminarayan $R$ (2016). Trends in antibiotic resistance among major bacterial pathogens isolated from blood cultures tested at a large private laboratory network in India, 20082014. Inter J Infec Dis 50:75-82.

15. Saeed NK, Kambal AM, \& El-Khizzi NA (2010). Antimicrobial-resistant bacteria in a general intensive care unit in Saudi Arabia. Saudi Med J 31(12): 1341-1349.

16. Haque R, \& Salam MA (2010). Detection of ESBL producing nosocomial Gram negative bacteria from a tertiary care hospital in Bangladesh. Pak J Med Sci 26(4): 887891.

17. Adedeji GB, Fagade OE, \& Oyelade AA (2007). Prevalence of Pseudomonas aeruginosa in clinical samples and its sensitivity to citrus extract. Afr J Biomed Res 10(2): 183-7.

18. Ogisi FO, \& Osammor TY (1982). Bacteriology of chronic otitis media in Benin. Niger Med J 12: 187-190.
19. Narten M, Rosin N, Schobert M, \& Tielen P (2012). Susceptibility of Pseudomonas aeruginosa urinary tract isolates and influence of urinary tract conditions on antibiotic tolerance. Curr Microbiol 64(1): 7-16.

20. Anagaw B, Biadglegne F, Belyhun Y, \& Mulu A (2011). Bacteriology of ocular infections and antibiotic susceptibility pattern in Gondar University Hospital, North West Ethiopia. Ethiop Med $J$ 49(2): 117-123.

21. Hafeez R, Aslam M, Mir F, Tahir M, Javaid I, \& Ajmal AN (2009). Frequency of extended spectrum beta lactamase producing gram negative bacilli among clinical isolates. Biomedica 25(2): 112115.

22. Hospenthal DR, Crouch HK, English JF, Leach F, Pool J, Conger NG, Whitman TJ, Wortmann GW, Robertson JL, \& Murray CK (2011). Multidrug-resistant bacterial colonization of combat-injured personnel at admission to medical centers after evacuation from Afghanistan and Iraq. J Trauma Acute Care Surg 71(1): S52-S57.

23. Latif S, Anwar MS, \& Ahmad I (2009). Bacterial pathogens responsible for blood stream infection (BSI) and pattern of drug resistance in a tertiary care hospital of Lahore. Biomedica 25(2): 101-105. 